\title{
27 Root Architecture and Productivity of Three Grass Species under Salt Stress
}

Liping Wang, Junjie Yi, and Theo Elzenga

\section{CONTENTS}

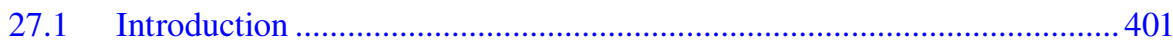

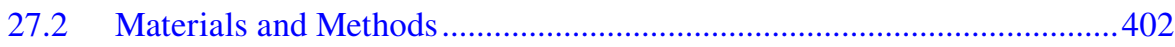

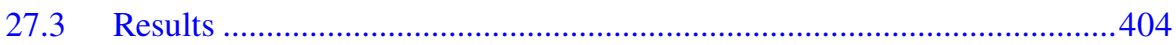

27.3.1 Effect of Salinity on Root Length...........................................404

27.3.2 Effect of Salinity on Root Architecture ......................................404

27.3.3 Effect of Salinity on Shoot and Root Productivity .....................407

27.3.4 Effect of Salinity on Root to Shoot Ratio ...................................408

27.4 Discussion..................................................................................... 410

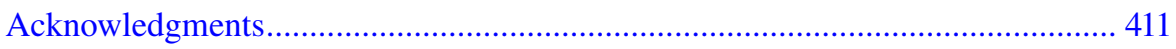

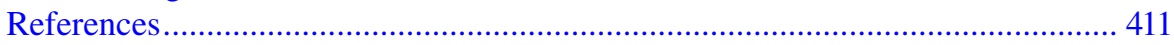

\subsection{INTRODUCTION}

Soil salinity severely limits the productivity and quality of crops and, therefore, poses a threat to food security throughout the world. Among the various abiotic stress factors, soil salinization is one of the most serious land degradation threats to modern agriculture. Increasing and more extensive salinization of arable land, combined with the projected growth of the human population, necessitates using more salt-tolerant crop plants.

The main functions of plant roots are anchoring the plant and the uptake of nutrients and water. Root system architecture (RSA) alludes to the spatial configuration of the root system and combines several structural features such as the length of primary roots and their spread, the number, angle and length of lateral roots and responds to external environmental conditions such as water availability, nutrition and ion concentrations in the soil (Khan et al., 2016). Grasses (Poaceae) have seminal roots, which consist of primary axes, formed during embryogenesis and already present in the un-germinated caryopsis, and the laterals which emerge from these with time (Leszek, 2012). Water and nutrient capture depends largely on laterals of seminal roots and rhiszosphere properties (Ahmed et al., 2018; Carminati et al., 2017; Boudiar et al., 2020). Under salt stress, the RSA of grasses can be reshaped in 
various ways. Salt stress has been shown to block primary root meristem division and inhibit cell elongation, causing inhibition and alterations to cell morphology, in combination with changing root length and the number of primary, lateral and seminal roots (Potters et al., 2007).

As RSA is highly variable and responds plastically to environmental conditions, it is considered a new target for breeding efforts. An efficient RSA improves plant growth and health by improving nutrient and water uptake under stress conditions, including salinity (Li et al., 2018; Berg et al., 2018). Salt-marsh grasses offer natural examples of plants with high salt tolerance and understanding their properties and strategies could yield critical parameters to be used in screening for crop plant varieties with potentially high salt tolerance. Native salt-marsh species have adapted to frequent flooding with sea water and are considered to be potentially highly salt tolerant (Rouger and Jump, 2015). Puccinellia maritima, or common salt-marsh grass, is one of the dominant grass species on salt marshes in Western Europe and is an important food source for migrating geese in early spring (Fokkema et al., 2016). Festuca rubra is another dominant species on saltmarshes but can also be found on non-saline soils (Gray and Scott 1977; Rouger et al., 2014).

In this study, we compared these two salt marsh grass species to Lolium perenne, a perennial pasture grass, widely used as fodder for cows and sheep, that can potentially also be used for biofuel purposes (Jauhar, 1993). To identify the relevant traits for salt-stress tolerance, we measured the development of the root systems and productivity of the three species under both control and saline conditions.

\subsection{MATERIALS AND METHODS}

Caryopses of grasses were germinated in 5-liter containers filled with vermiculite moistened with tap water. After germination, uniform seedlings with one leaf were selected and transferred to plastic pots filled with vermiculite and placed in a culture room (temperature $22 / 18^{\circ} \mathrm{C}$, light/dark: $14 \mathrm{~h} / 8 \mathrm{~h}, 150 \mu \mathrm{mol} \mathrm{m}{ }^{-2} \mathrm{~s}^{-1}$ ). The seedlings were watered with tap water every day till the third leaf reached $3 \mathrm{~cm}$. After that, the seedlings were watered with a $25 \%$ Hoagland solution for 4 days. At day 18 after germination, the salt treatment started. The $25 \%$ Hoagland solution was supplemented with $\mathrm{NaCl}$. To avoid salt shock, the salinity was applied gradually with stepwise increases of $25 \mathrm{mM} \mathrm{NaCl}$, every 2-3 days, until the final concentrations of 50, 100, 150 and $200 \mathrm{mM}$ were reached. Plant samples were taken at 3, 6, 9 and 12 days after the final $\mathrm{NaCl}$ concentration was reached. Each pot contained three plants, and for each treatment three replicates were used.

When sampling, whole plants were carefully removed from the pots and rinsed under running tap water to remove any adhering vermiculite, avoiding any damage to the roots. Subsequently, the roots were stained in a solution of $0.5 \mathrm{~g} / \mathrm{L}$ Neutral Red for $10 \mathrm{~min}$ and rinsed 5 times in distilled water. The roots were spread out to reduce crossing roots as much as possible on an Epson 10000 flatbed scanner controlled by WinRhizo, Arabido 2009 software. The images of the scanner were cropped to size and color inverted with Paint and then analyzed with RootNav 2.0 software, making distinctions between primary roots, seminal roots and lateral roots (Figure 27.1 for a schematic representation of the root architecture). Since there is no option for 

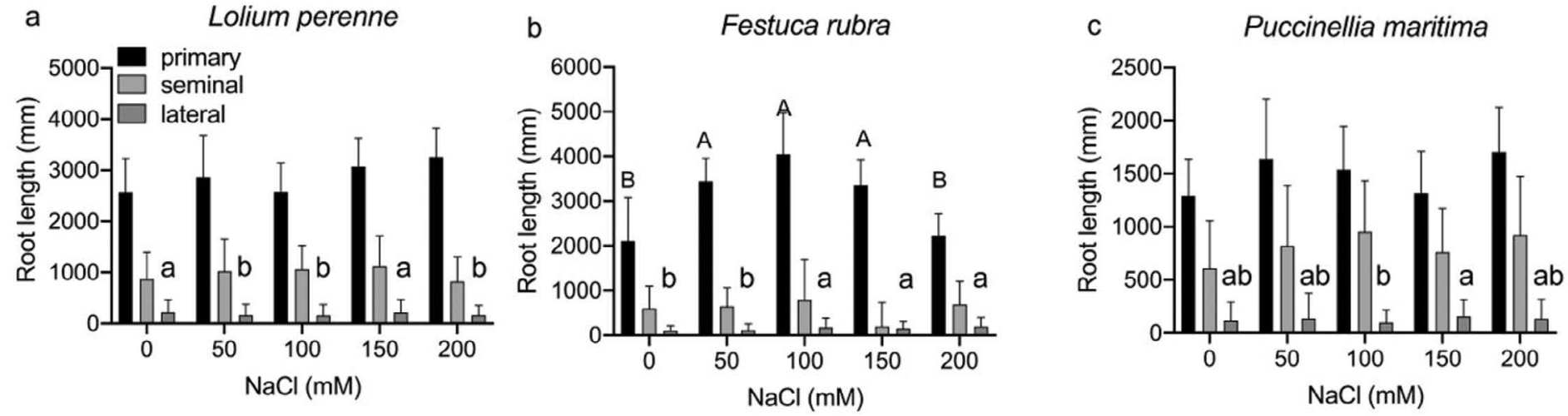

FIGURE 27.1 Effect of salinity on root length after 9-day of exposure to NaCl. Samples were taken at 3-day, 6-day, 9-day and 12-day after start of the salt treatment. Five salt concentrations were used: $0 \mathrm{mM}$ (control) $50 \mathrm{mM}, 100 \mathrm{mM}, 150 \mathrm{mM}, 200 \mathrm{mM} \mathrm{NaCl}(\mathrm{n}=9)$. 
seminal roots in this software, the primary roots were marked as $1^{\text {st }}$ primary and the other seminal roots were marked as sequential lower order primaries. The statistical analysis ANOVA using the Tukey test was performed using Prism (version 8 for MacOs, Graphpad).

The fresh weight of roots and shoots were measured directly after scanning of the root system. Three replicate seedlings in one pot were weighed together to increase accuracy since individual seedlings were still small.

For determination of the RSA parameters, the 12-day old plants of $L$. perenne were too large to be analyzed by RootNav. The analysis of Lolium plants could, therefore, only be followed up to day 9 . To determine the effect of salinity on growth rate and RSA, root and shoot weight and its ratio denoted as R/Sh, the relative ratios of results under 100 or $200 \mathrm{mM} \mathrm{NaCl}$ and control treatments were calculated according to formulas 27.1 and 27.2

$$
\begin{aligned}
& \left(\text { value }_{100 \mathrm{mM}}-\text { value }_{0 \mathrm{mM}}\right) / \text { value }_{0 \mathrm{mM}} \times 100 \% \\
& \left(\text { value }_{200 \mathrm{mM}}-\text { value }_{0 \mathrm{mM}}\right) / \text { value }_{0 \mathrm{mM}} \times 100 \% .
\end{aligned}
$$

\subsection{RESULTS}

\subsubsection{Effect of Salinity on Root Length}

Salinity affected the primary root length (PRL) differently in the three grass species studied (Figure 27.2). The PRL of Lolium perenne and Puccinellia maritima was increased when exposed to $\mathrm{NaCl}$, but Festuca rubra showed a significant increase $(P=0.05)$ at intermediate salt concentrations, a stimulation that was no longer apparent at $200 \mathrm{mM} \mathrm{NaCl}$.

The seminal root length (SRL) of the three grass species also showed an increase with salinity, but this difference was not significant. Compared with the PRL, the SRL of L. perenne was much shorter. The SRL ranged from $6 \%$ to $45 \%$ of the PRL in L. perenne and F. rubra and was not affected significantly by salinity. In contrast, the SRL of $P$. maritima was very low at $0 \mathrm{mM} \mathrm{NaCl}(4 \%)$ but increased strongly (by $50-62 \%$ ) when exposed to salinity.

The effect of salinity on lateral root length (LRL) differed significantly between the three species. The LRL of L. perenne was highest in the control plants and was reduced significantly at the higher salinity levels. In contrast, the LRL of $F$. rubra was highest under high salinity $(100,150$ and $200 \mathrm{mM} \mathrm{NaCl})$ and was lower at 0 and $50 \mathrm{mM} \mathrm{NaCl}$. In $P$. maritima the LRL was relatively high under all salinity conditions but was not strongly affected by high salinity levels.

\subsubsection{Effect of Salinity on Root Architecture}

Root architecture was strongly affected by salinity stress as shown in Table 27.1. The total SRL increased in L. perenne at $100 \mathrm{mM} \mathrm{NaCl}$ compared to control, but the contribution of the lateral roots decreased (lateral root total length by $-32 \%$ and $-36 \%$ at 100 and $200 \mathrm{mM} \mathrm{NaCl}$, respectively). F. rubra showed the most positive increases 
Lotim shout

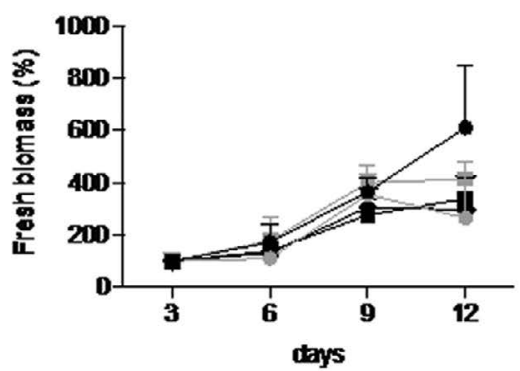

Lolimm mot

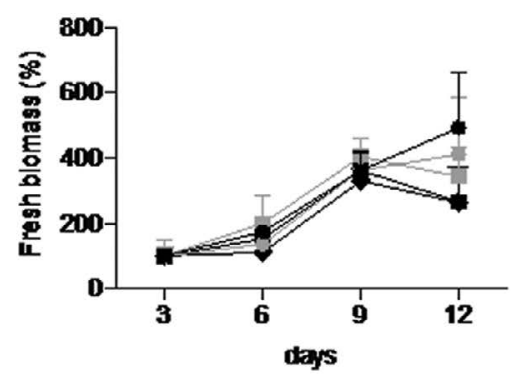

Festura shout

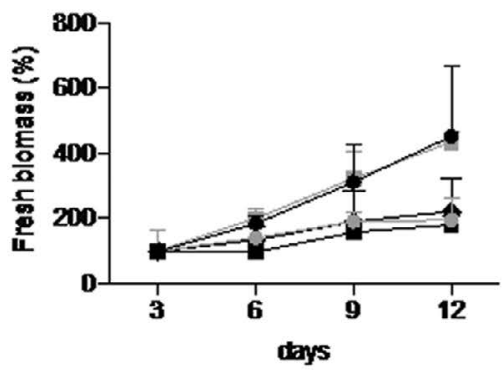

Festuca rout

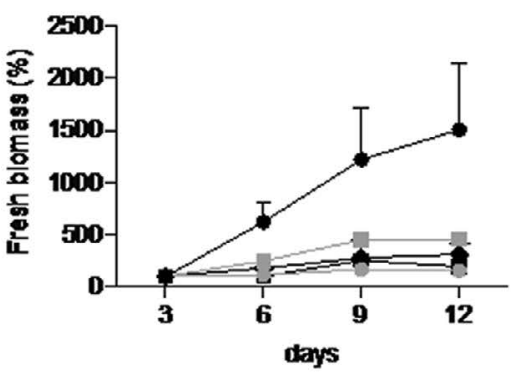

Puccinelia shoot

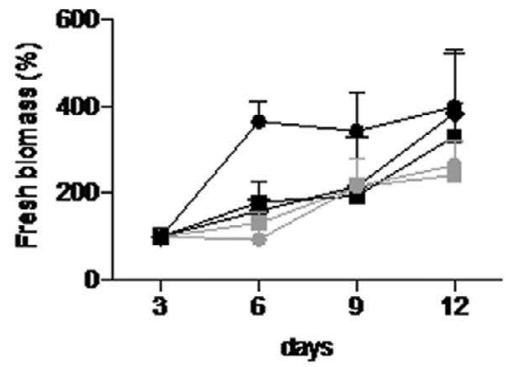

Purcinelia mot

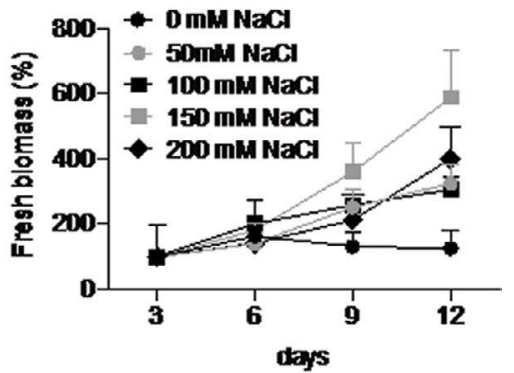

FIGURE 27.2 Effect of salinity on root and shoot productivity of three grasses. Uniform germinated seedlings with one leaf of $F$. rubra, P. maritima, and L. perenne were transferred to pots with vermiculite and watered with $25 \%$ Hoagland solution. Salt treatments started $\sim 17-18$ days after germination. Salt was gradually added to plants to avoid the salinity shock. End concentration $\mathrm{NaCl}$ were $0,50,100,150,200 \mathrm{mM}$, samples were taken at 3, 6, 9, 12 days after start of the salinity treatment $(n=3)$. The top 6 panels indicate the increase in biomass in shoot and root in $\%$ (biomass at day $3=100 \%$ ). The bottom 6 panels indicate the calculated relative growth rate (RGR) based on the data in the top panels. 

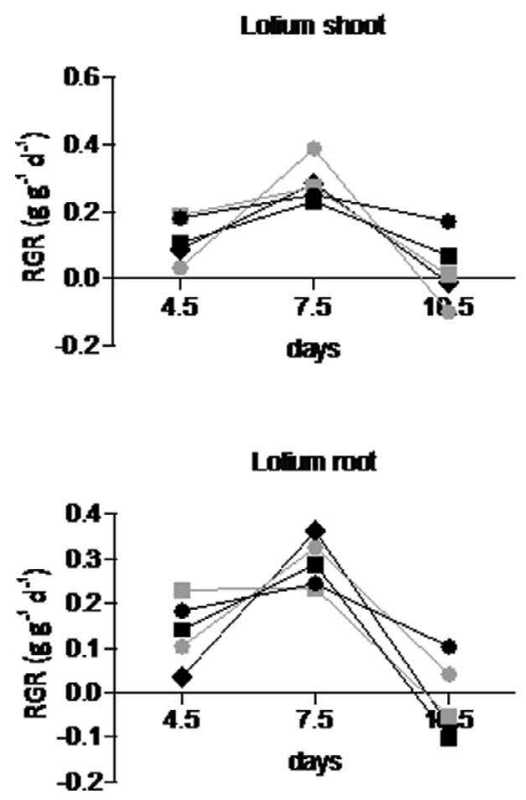

Festura shoot

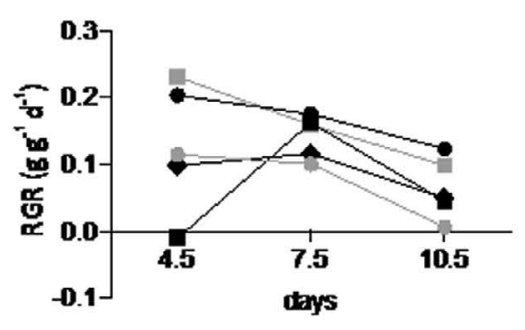

Festura root

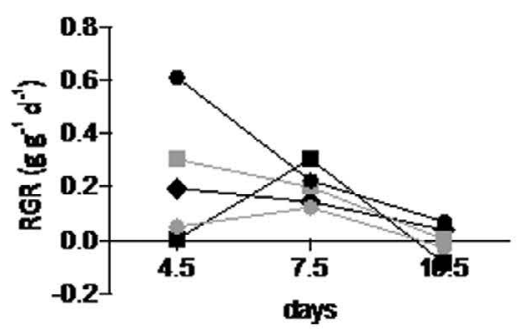

(b)

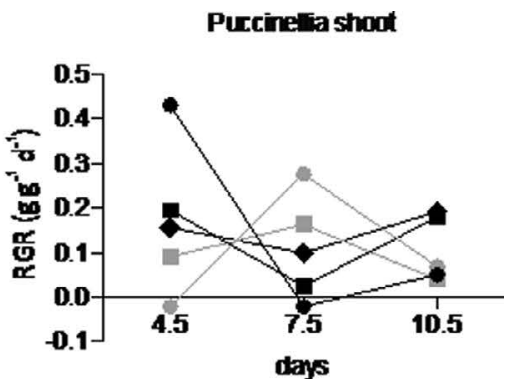

Purcinelia root

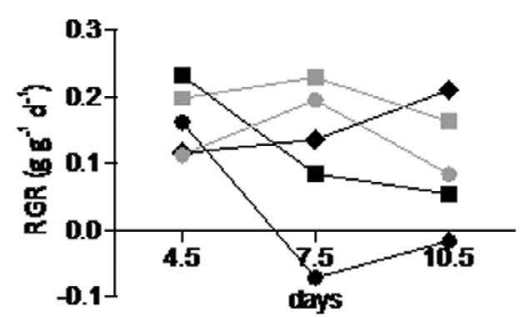

FIGURE 27.2 (Continued) 


\section{TABLE 27.1}

\section{Percentage $\mathrm{NaCl}$-Induced Change in Root Architecture Parameters}

\begin{tabular}{|c|c|c|c|c|c|c|c|c|}
\hline & $\begin{array}{l}\mathrm{NaCl} \\
(\mathrm{mM})\end{array}$ & $\begin{array}{l}\text { Primary } \\
\text { Length }\end{array}$ & $\begin{array}{l}\text { Seminal } \\
\text { Number }\end{array}$ & $\begin{array}{c}\text { Seminal } \\
\text { Mean } \\
\text { Length }\end{array}$ & $\begin{array}{c}\text { Seminal } \\
\text { Total } \\
\text { Length }\end{array}$ & $\begin{array}{l}\text { Lateral } \\
\text { Number }\end{array}$ & $\begin{array}{l}\text { Lateral Mean } \\
\text { Length }\end{array}$ & $\begin{array}{l}\text { Lateral Total } \\
\text { Length }\end{array}$ \\
\hline L. perenne & $100^{1}$ & 0 & 1 & 1 & 37 & -6 & -19 & -32 \\
\hline F. rubra & 100 & 86 & -3 & 11 & 8 & 134 & 92 & 279 \\
\hline P. maritima & 100 & 16 & 34 & 1 & 126 & -6 & -20 & -12 \\
\hline L. perenne & $200^{2}$ & 27 & -5 & -5 & 9 & -13 & -14 & -36 \\
\hline F. rubra & 200 & 6 & -13 & 15 & 0 & 46 & 75 & 128 \\
\hline P. maritime & 200 & 29 & 11 & 11 & 86 & 25 & 1 & 60 \\
\hline
\end{tabular}

among three grasses. Apart from the seminal root number (a moderate decrease of $-3 \%$ and $-13 \%$ at 100 and $200 \mathrm{mM} \mathrm{NaCl}$, respectively) all the other 6 parameters of root architecture increased at both 100 and $200 \mathrm{mM} \mathrm{NaCl}$, the highest being the lateral root total length by $279 \%$. However, for primary root, lateral root and seminal root (except for number of seminal root), an inhibition by $200 \mathrm{mM}$ compared to $100 \mathrm{mM}$ $\mathrm{NaCl}$ was apparent.

Each treatment has 9 replicates. Indicated is the percentage change after 9 days of exposure to $\mathrm{NaCl}$ in the nutrient solution compared to the control treatment.

Contrary to $F$. rubra, with $P$. maritima the highest stimulation was observed at $200 \mathrm{mM}$ : both primary and seminal total root length of $P$. maritima increased at both 100 and $200 \mathrm{mM}$ relative to the control. The seminal total length increased by $126 \%$ at $100 \mathrm{mM} \mathrm{NaCl}$. Although the primary and seminal roots showed an increase at $100 \mathrm{mM}$, the lateral roots showed a slight decrease. This trend continues at $200 \mathrm{mM}$ : the 7 root traits consistently increased in P. maritima especially with the seminal total length (87\%), while the lateral length was not affected (1 to $2 \%$ in lateral mean length).

\subsubsection{Effect of Salinity on Shoot and Root Productivity}

Figure 27.2 shows the development of root and shoot fresh weight relative to the fresh weight present at day 3. Comparing the overall pattern of biomass increase for the three species, we observed very distinct differences. Although in all species growth was highest in the control (with the interesting exception of $P$. maritima, where prolonged exposure did show more or equal growth in the presence of $\mathrm{NaCl}$ ), comparing the immediate (day 6) and post-acclimation (day 12) does yield some interesting differences. In L. perenne, the exposure to salt did not result in a significant inhibition of growth. Up to day 9, there was identical growth in both shoot and root in all treatments. However, at day 12 the high $\mathrm{NaCl}$ treatments did lead to such a strong effect that the root biomass showed a negative trend. In F. rubra, exposure to salinity 

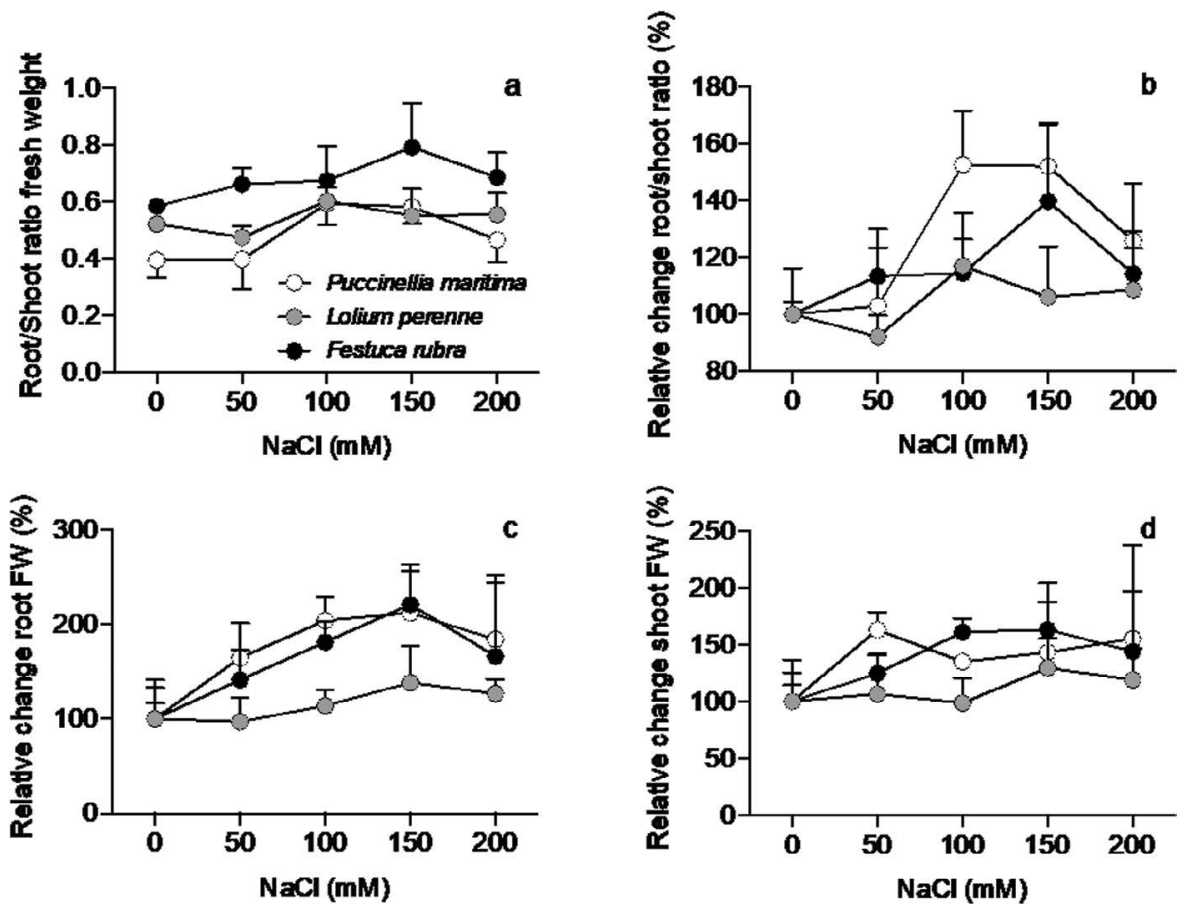

FIGURE 27.3 Effect of salinity on root shoot ratio after 9 days of growth. See legend to Figure 9.2 for details. Fresh Root shoot (R/Sh) ratio, salt to control Fresh R/Sh ratio and salt to control fresh root and fresh shoot were calculated based on fresh root and shoot weight. (a) Fresh Root Shoot weight ratio. (b- d) The R/Sh, Root weight and Shoot divided by the control, respectively $(n=9)$.

induced an immediate growth reduction in both root and shoot and this growth reduction was present at a constant level throughout the whole 12 days period. A third pattern is observed in $P$. maritima where $\mathrm{NaCl}$ did have an instant effect leading to growth inhibition at day 6. However, this effect was transient, and at day 12 the growth in the presence of $\mathrm{NaCl}$ was as vigorous as under control conditions. In all three species, the observed patterns were most manifest in root biomass, but were also visible in the shoot development.

\subsubsection{Effect of Salinity on Root to Shoot Ratio}

The fresh weight data at day 9 were used to analyze the effect of increasing salinity on the root the shoot ratio (R/Sh). In Figure 27.4a, the ratios are directly plotted and although already differences the effect of salinity can be discerned, the difference became more apparent when we calculated the relative (compared to control) salinityinduced change in R/Sh (Figure 27.4b). The relative R/Sh of L. perenne did not significantly change, whereas in both $F$. rubra and $P$. maritima the R/Sh increased with salinity, only to drop again at the highest $\mathrm{NaCl}$ concentration. This increase in 


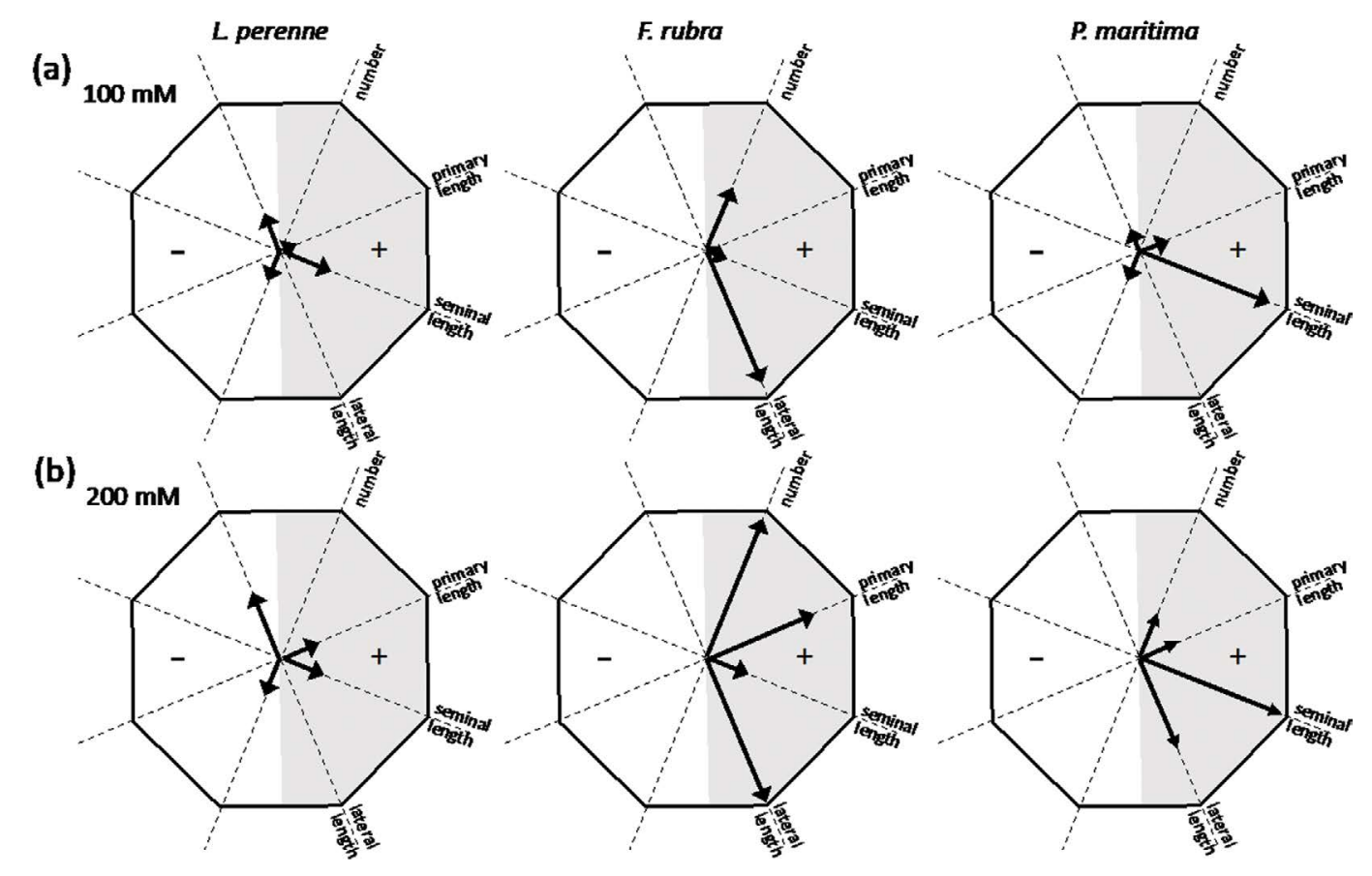

FIGURE 27.4 The effect of 100 and $200 \mathrm{mM} \mathrm{NaCl}$ on the following root architecture parameters: root number, primary root length, seminal root length and lateral root length. An arrow pointing to the white (left hand) half indicates a decrease in the indicated parameter, an arrow pointing to the grey (right hand) half indicates an increase in the parameter value. (a) The effect of $100 \mathrm{mM} \mathrm{NaCl}$ compared to the control conditions, (b) the effect of $200 \mathrm{mM} \mathrm{NaCl}$. The changes are relative to the control (no salt) values and calculated by:

(index ${ }_{100 \mathrm{mM}}-$ index $_{0 \mathrm{mM}}$ ) / index $0 \mathrm{mM} * 100 \%$ for $100 \mathrm{mM}$ compared to control and $\left(\right.$ index $_{200 \mathrm{mM}}-$ index $_{0 \mathrm{mM}}$ ) $/$ index $_{0 \mathrm{mM}} * 100 \%$ for $200 \mathrm{mM}$ compared to control. 
$\mathrm{R} / \mathrm{Sh}$ in the two salt marsh species was caused by a relative increase in the root fresh weight with salinity, while the shoot biomass was not affected. In L. perenne, $\mathrm{NaCl}$ did not induce a similar increase in root biomass, resulting in a constant R/Sh.

\subsection{DISCUSSION}

Salinity had a significant effect on RSA in all three species in this study. However, the way the root system architected was affected differed between species. The patterns are summarized in Table 27.2. In the comparison between the species, we have mainly taken data of day 9 of the salinity treatment, a time point when the detrimental effects of high salinity were not yet apparent in L. perenne, the most salinity sensitive species. At the higher salinity levels, the $L$. perenne showed a reduction in biomass (negative growth) at day 12 and although the patterns were even more pronounced, it is likely that from that day on physiological processes were not within the normal operational range and would have introduced an unwanted bias.

Most of the results we obtained confirm that L. perenne is a moderately saltsensitive species. In short-term experiments, the plant behaves as an excluder, maintaining growth when exposed, probably by excluding $\mathrm{Na}^{+}$from entering the plant. This strategy fails at longer exposure periods as is evident from the reduction in root biomass at day 12 .

F. rubra and $P$. maritima exhibit radically different patterns, both different from L. perenne, but also from each other. At moderate levels of salinity, F. rubra increases strongly in the number and length of its lateral roots (Figure 27.2 and Tables 27.1, 27.2), reduces its shoot growth (Figure 27.3) and increases R/Sh ratio. All these adjustments to the growth pattern indicate an acclimation to a more restricted uptake of water and nutrients (Koevoets et al. 2016). Effectively, the F. rubra invests in the root system, increasing its uptake potential, while simultaneously decreasing the demand for nutrients (reduction of shoot growth) and water (smaller shoot leads to less evaporating leaf surface).

\section{TABLE 27.2}

\section{Salinity-Induced Changes in Root Architecture after 9-Day of Exposure}

\begin{tabular}{|c|c|c|c|c|c|c|c|c|}
\hline & \multicolumn{4}{|c|}{$100 \mathrm{mM} \mathrm{NaCl}{ }^{1}$} & \multicolumn{4}{|c|}{$200 \mathrm{mM} \mathrm{NaCl} 2$} \\
\hline & $\begin{array}{l}\text { Primary } \\
\text { Length }\end{array}$ & $\begin{array}{c}\text { Seminal } \\
\text { Length }\end{array}$ & $\begin{array}{l}\text { Lateral } \\
\text { Length }\end{array}$ & $\begin{array}{c}\text { Lateral } \\
\text { Number }\end{array}$ & $\begin{array}{l}\text { Primary } \\
\text { Length }\end{array}$ & $\begin{array}{c}\text { Seminal } \\
\text { Length }\end{array}$ & $\begin{array}{l}\text { Lateral } \\
\text { Length }\end{array}$ & $\begin{array}{c}\text { Lateral } \\
\text { Numbe }\end{array}$ \\
\hline L. perenne & + & + & -- & -- & ++ & + & -- & - \\
\hline F. rubra & +++ & ++ & +++++ & ++++ & + & + & ++++ & ++ \\
\hline P. maritima & ++ & +r++ & -- & - & ++ & +++ & +++ & ++ \\
\hline
\end{tabular}

The relative percentage were calculated by Salt effect: (salt-control)/control*100\%

$0 \sim 10 \%$ : +; 10\% 50\%: ++; >50\%: +++; >100\%: ++++; >200\%: +++++

0 - 10\%: -; -10\% -50\%: - - <-50\%: - - - <-100\%: - - - - <-200\%: - - - - .

1 Comparison of $100 \mathrm{mM} \mathrm{NaCl}$ to control (index ${ }_{100 \mathrm{mM}}-$ index $_{0 \mathrm{mM}}$ ) $/$ index $_{0 \mathrm{mM}} * 100 \%$.

2 Comparison of $200 \mathrm{mM} \mathrm{NaCl}$ to control (index $200 \mathrm{mM}-$ index $_{0 \mathrm{mM}}$ ) $/$ index $_{0 \mathrm{mM}} * 100 \%$. 
P. maritima also increases its effective root system, but does so by increasing its primary, seminal and lateral root system. Remarkable is the stepwise increase: increasing primary and seminal roots at moderate salinity and mainly lateral root at the highest $\mathrm{NaCl}$ concentration. The overall growth of $P$. maritima (both shoot and root growth) is not significantly affected after an acclimation period of 3 to 6 days, making $P$. maritima in our study the most salinity tolerant species.

Although both $F$. rubra and $P$. maritima were effective in coping with salinity, the differences do confirm the relatively higher salinity tolerance of P. maritima, true to its ecological niche on the lower salt marsh. This comparative study clearly shows that grasses that are (highly) adapted to saline conditions are capable of restructuring their architecture by specifically investing in the development of lateral and seminal roots, increasing their capacity to take up water and nutrients. In breeding programs, these traits could be exploited, with the caveat that these traits could come at a cost, as they are in our examples associated with (temporary) reduced above ground productivity.

\section{ACKNOWLEDGMENTS}

Acknowledgments are due to Ms. Zhang Yan Pudussery for help in isolating uniform seedling for this experiment, and to Dr. Jan Henk Venema for introducing instrument and software of root scanning. Thanks to the USDA-ARS for providing the seeds of P. maritima. This mention of trade names or commercial products is solely for the purpose of specific information and does not imply recommendation or endorsement by the U.S. Department of Agriculture Research Service. Thanks for the support from the China Scholarship Council (CSC) and the University of Groningen. Author Contributions Wang, Liping and Theo Elzenga conceptualized and designed the experiments; Wang, L performed evaluation of root system archtecture and productivity parameters; Wang, L, Yi, J and Theo Elzenga analyzed the data; The manuscript was written jointly with contributions from all the authors. All authors have read and approved the manuscript.

\section{REFERENCES}

Ahmed, M.A., Zarebanadkouki, M., Meunier, F., Javaux, M., Kaestner, A., and Carminati, A. (2018) Root type matters: Measurement of water uptake by seminal, crown, and lateral roots in maize. Journal of Experimental Botany 69, 1199-1206. https://doi.org/10.1093/ jxb/erx 439

Berg, T. van den and Tusscher, K.H. (2018) Lateral root priming synergystically arises from root growth and auxin transport dynamics. bioRxiv 361709. https://doi. org/10.1101/361709

Boudiar, R., Casas, A.M., Gioia, T., Fiorani, F., Nagel, K.A., and Igartua, E. (2020) Effects of Low Water Availability on Root Placement and Shoot Development in Landraces and Modern Barley Cultivars. Agronomy 10, 134. https://doi.org/10.3390/ agronomy10010134

Carminati, A., Benard, P., Ahmed, M.A. et al. (2017) Liquid bridges at the root-soil interface. Plant Soil 417, 1-15. https://doi.org/10.1007/s11104-017-3227-8

Fokkema,W., de Boer, W., van der Jeugd, H.P., Dokter, A., Nolet,B.A., De Kok, L.J., Elzenga, J.T.M., and Olff, H. (2016) The nature of plant adaptations to salinity stress has trophic consequences. Oikos 125, 804-811. doi: 10.1111/oik.02757 
Gray, A.J. and Scott, R. (1977) Puccinellia maritima (Huds.) Parl.: (Poa maritima Huds.; Glyceria maritima (Huds.) Wahlb.). Journal of Ecology 65, 699-716.

Jauhar P. P. (1993). Cytogenetics of the Festuca-Lolium complex: Relevance to breeding. Berlin: Springer. pp. 1-8

Khan, M.A., Gemenet, D.C., and Villordon, A. (2016) Root system architecture and abiotic stress tolerance: Current knowledge in root and tuber crops. Frontiers in Plant Science 7, 1584. https://doi.org/10.3389/fpls.2016.01584

Koevoets, I., Venema, J.H., Elzenga, J.T.M., and Testerink, C. (2016) Roots withstanding their environment: Exploiting root system architecture responses to abiotic stress to improve crop tolerance. Frontiers in Plant Science 7(112), 1335. doi: 10.3389/fpls.2016.01335

Leszek, P. and Vincent, D. (2012) Maize (Zea mays)Gross Anatomy Ontology - seminal root system - Classes NCBO BioPortal. http://bioportal.bioontology.org/ontologies/ZEA

Li, P., Zhang, Y., Yin, S., Zhu, P., Pan, T., Xu, Y., Wang, J., Hao, D., Fang, H., Xu, C., and Yang, Z. (2018) QTL-by-environment interaction in the response of maize root and shoot traits to different water regimes. Frontiers in Plant Science 9, 229. doi:10.3389/ fpls.2018.00229

Potters, G., Pasternak, T., Guisez, Y., and Palme, K. (2007) Stress-induced morphogenic responses: growing out of trouble? Trends in Plant Science, 12, 98-105. doi: 10.1016/j. tplants.2007.01.004

Rouger, R., Vallejo-Marin, M., and Jump, A.S. (2014) Development and cross-species amplification of microsatellite loci for Puccinellia maritima, an important engineer saltmarsh species. Genetics and Molecular Research 13, 3426-3431. doi: 10.4238/2014.April.30.3

Rouger, R. and Jump, A.S. (2015) Fine-scale spatial genetic structure across a strong environmental gradient in the saltmarsh plant Puccinellia maritima. Evolutionary Ecology 29, 609-623. https://doi.org/10.1007/s10682-015-9767-6

Schnepf, A., Leitner, D., Landl, M., Lobet, G., Hieu, Mai, T. H., Morandage, S., Sheng, C., Zörner, M., Vanderborght, J., and Vereecken, H. (2018) CRootBox: A structuralfunctional modelling framework for root systems. Annals of Botany 121, 1033-1053. doi:10.1093/aob/mcx221

Sparks, E.E. and Benfey, P.N. (2017) The contribution of root systems to plant nutrient acquisition. M.A. Hossain, T. Kamiya, D.J. Burritt, L.S.P. Tran, T. Fujiwara (Eds.), Eds.), In: Plant Macronutrient Use Efficiency, Academic Press, London, UK, pp. 83-92. doi:10.1016/B978-0-12-811308-0.00005-3 